\title{
Effect of Mulligan Technique on Subacromial Impingement Syndrome: A Systematic Review Mohamed Abdellatif Hassan ${ }^{1 *}$, Enas Fawzy Elanni², Karima Abdelaty Hassan ${ }^{2}$, Karim Ghuiba ${ }^{2}$ \\ ${ }^{1}$ Department of Physiotherapy, Misr International Hospital, Giza, Egypt \\ ${ }^{2}$ Department of Physical Therapy for Musculoskeletal Disorders and Its Surgery, Faculty of Physical Therapy, Cairo University, Egypt. \\ *Corresponding author: Mohamed Abdellatif Hassan, Mobile: (+20) 01111028319, E-Mail: elmezaien@yahoo.com
}

\begin{abstract}
Background: Subacromial impingement syndrome (SIS) is considered the most prevailing cause of shoulder pain. Although Mulligan's technique may be useful in treating shoulder impingement, its significance in areas of range of movement (ROM), pain, and function is still debated.

Objective: To systematically review and summarize the best evidence on treating subacromial impingement syndrome using mobilization with movement.

Patients and Methods: Databases Cochrane Library Web search, PEDro and PubMed were searched for RCTs published in English language from inception to September 2019, updated later to 7th of July 2021. Reference lists of relevant publications were also screened. Two reviewers separately identified relevant papers based on the inclusion criteria. The identified papers by both authors were obtained in full text. To evaluate methodological quality and risk of bias, the Cochrane risk of bias tool was used. We used the random-effects model in all analyses for meta-analyses.

Results: A total of 11 RCTs with a total number of 358 adults with subacromial shoulder pain were included. They examined the effect of mobilization with movement (MWM) combined with exercise with or without taping against rotator cuff strengthening, ROM exercises, isometric strengthening, shoulder joint mobilization, and sham techniques. Meta-analysis was done comparing MWM against exercise and found a significant difference in VAS and a non-significant difference in SPADI.

Conclusion: Shoulder mobilization with movement combined with a supervised exercise program (ROM, and functional limitations) has a better impact on pain than exercise alone or sham in short-term with similar improvement to exercise in the long-term.
\end{abstract}

Keywords: Shoulder impingement, Mobilization with movement, Mulligan.

\section{INTRODUCTION}

Shoulder impingement contributes to $44-60 \%$ of all disorders causing shoulder pain, makes it the most familiar cause of shoulder pain ${ }^{(1)}$. Shoulder impingement syndrome can be caused by several factors include weakness of the rotator cuff muscles, morphology of the acromion, muscle imbalance, laxity or tightness of the joint capsule, dysfunctional glenohumeral and scapulothoracic kinematics, degeneration and the tendons or bursa inflammation $^{(2)}$. Subacromial impingement is distinguished by painful shoulder, elevation or overhead activities of the arm aggravate pain in adults. It has a huge impact on socioeconomic status due to individual's working ability limitation ${ }^{(3,4)}$.

Various physical therapy interventions, which include thermotherapy, electrotherapy, therapeutic exercise therapy, and manual physical therapy are used to treat impingement of the shoulder ${ }^{(5)}$. Therapeutic exercises generally have a positive effect in restoring shoulder mobility and retraining muscle imbalance in SIS ${ }^{(6,7,8)}$. Exercise therapy was described by Haik et $\boldsymbol{a l} .{ }^{(\mathbf{9})}$ as the first choice to improve function, range of movement and pain and range of motion in treatment of shoulder. The reduction of pain can be accelerated in the short-term by adding of mobilizations to exercises. Mobilization with movement (MWM) is a manual therapy technique used for musculoskeletal pain management. The therapist applies a sustained glide to a painful or stiff joint while the patient performs a concurrent active movement ${ }^{(10)}$. Mulligan ${ }^{(10)}$ advocated that MWM is clinically useful when a single application exhibits a measurable pain and range of movement improvement in joint.

A recent systematic review Stathopoulos $\boldsymbol{e t}$ al. studied the effect of mulligan's technique on peripheral joints, concluded that MOM for shoulder adhesive capsulitis and hip pain produced not only a statistically significant but also, a clinically significant ROM increase in all movement directions. On the contrary, a therapeutic benefit regarding ROM for shoulder impingement syndrome, shoulder dysfunction / pain, tight hamstring, knee arthritis, and chronic instability of the ankle could not be obviously settled ${ }^{(11)}$.

The strength of evidence concerned with the clinical efficacy of Mulligan MOM is not clear. The purpose of this study was systematically reviewing the best evidence on the effectiveness of using Mulligan 
mobilization in patients with subacromial impingement to guide the development of standardized clinical guidelines. This could help directing clinical decision making by the physical therapists need to implement those applications or not.

\section{MATERIALS AND METHODS}

The review was cataloged on PROSPERO (PROSPERO 2020: CRD CRD42020162989) and executed according to PRISMA guidelines (Preferred Reporting Items for Systematic Reviews and Metaanalyses) ${ }^{(12)}$.

The electronic databases Cochrane Library Web search, PEDro (physiotherapy and evidence database) MEDLINE / PubMed were searched for RCTs published in English language from inception to September 2019, updated later until 7th of July 2021. Also, reference lists of relevant papers were checked.

\section{Search strategy:}

The following terms were used in the electronic databases for identifying articles: shoulder, glenohumeral, subacromial, rotator cuff, coracohumeral and internal. Moreover, mobilization with movement, Mulligan, posterolateral mobilization, inferior mobilization, hand behind back mobilization. Also, impingement*, tendinitis, tendinopathy and pain*.

Database search formulas are presented in (Appendix1). The criteria for inclusion and exclusion are shown in (Table 1).

\section{Appendix (1): Search strategy and number of papers found in each database}

\begin{tabular}{|c|c|c|}
\hline Database & Number of citations & Keywords \\
\hline PubMed & $\begin{array}{l}\text { Original } 176 \\
\text { Update } 88\end{array}$ & $\begin{array}{l}\text { Shoulder, glenohumeral, subacromial, rotator cuff, } \\
\text { coracohumeral, internal, mobilization with movement, Mulligan, } \\
\text { posterolateral mobilization, inferior mobilization, hand behind } \\
\text { back mobilization, impingement* tendinitis, tendinopathy and } \\
\text { pain*. } \\
\text { Filters: } \\
\text { Clinical trial } \\
\text { Humans }\end{array}$ \\
\hline Cochrane & $\begin{array}{l}\text { Original } 106 \\
\text { Update } 55\end{array}$ & $\begin{array}{l}\text { \#1 shoulder } \\
\text { \#2 rotator cuff } \\
\text { \#3 coracohumeral } \\
\text { \#4 subacromial } \\
\text { \#5 internal } \\
\text { \#6 glenohumeral } \\
\text { \#7 \#1 OR \#2 OR \#3 OR \#4 OR \#5 OR \#6 } \\
\text { \#8 impingement* syndrome } \\
\text { \#9 tendinitis } \\
\text { \#10 tendinopathy } \\
\text { \#11 pain* } \\
\text { \#12 \#8 OR \#9 OR \#10 OR \#11 } \\
\text { \#13 \#7 AND \#12 } \\
\text { \#14 mobilization with movement } \\
\text { \#15 mulligan } \\
\text { \#16 posterolateral mobilization } \\
\text { \#17 inferior mobilization } \\
\text { \#18 hand behind back mobilization } \\
\text { \#19 \#13 OR \#14 OR \#15 OR \#16 OR \#17 OR \#18 } \\
\text { \#20 \#13 AND \#19 }\end{array}$ \\
\hline PEDro & $\begin{array}{l}\text { Original } 346 \\
\text { Update } 28\end{array}$ & $\begin{array}{l}\text { Mobilization with movement. } \\
\text { Mulligan. } \\
\text { Impingement }\end{array}$ \\
\hline
\end{tabular}


Table (1): Eligibility criteria of the included studies

\begin{tabular}{|l|}
\hline Studies that were eligible for inclusion: \\
- \\
Published randomized controlled trials. \\
Trials that enrolled adult population (over 18 \\
- Subacromial impingement. \\
- Either Acute, sub-acute or chronic. \\
Mobilization with Movement: Posterolateral \\
mobilization. Inferior mobilization (hand \\
behind back). \\
Studies that compared MWM to control, \\
placebo, or standard care and studies that \\
compared different doses, intensities, or timing \\
of delivery of the same intervention were \\
included. \\
Studies that were excluded: \\
- Study designs other than randomized- \\
controlled trials. \\
Review articles, surveys, case report, \\
conference meetings, and case series. \\
Published abstracts with no full-text articles \\
available. \\
Records in other languages than English, and \\
abstracts not available. \\
Invasive interventions, surgery, or \\
pharmacological therapy as the only treatment.
\end{tabular}

\section{Selection Criteria:}

Mendeley Desktop@ (version 1.19.5) was used to pool titles and abstracts. Duplicates and irrelevant articles that didn't meet the inclusion criteria were removed using the software. Based on the eligibility criteria two reviewers (Mohamed Abdellatif (MA) and Karim Ghuiba (KG)) independently identified papers as relevant. Both reviewers matched their lists. Full text of papers identified by both authors were obtained. Any judgment disagreements were resolved by consensus. A third reviewer (Karima A. Hassan (KAH)) acted as arbiter. A flow chart of study selection is presented in figure (1).

\section{Data extraction:}

(MA and KAH) single-handedly extracted the suitable data and compared their findings to verify whether all suitable data were well extracted. They extracted author, year of publication, title, characteristics of participants, intervention/control, treatment duration, outcome measures, statistical tests used, results, and conclusions.

\section{Assessment of risk of bias:}

Three researchers (MA, KG, and $\mathrm{KAH}$ ) unassisted evaluated the quality of selected articles by using the Cochrane risk-of-bias tool for randomized trials (RoB 2) Version 22 August 2019-assessment tool ${ }^{(24)}$. The structure of RoB 2 consisted of five main domains, emphasizing on different parts of trial design, conduct, and reporting. Each one of the domains contains a series of questions ('signaling questions') targeting information about the trial features that are relevant to the risk of bias. An algorithm is used for judgment about the risk of bias arising from each domain, according to answers to the signaling questions. Judgment could be 'Low' or 'High' risk of bias, or can express 'Some concerns'. These five main domains are: (1) bias due to defect in the randomization process, (2) bias caused by deviations from intended interventions, (3) bias because of missing outcome data, (4) bias in measurement of the outcome, (5) bias in selection of the reported result.

\section{Statistical methods:}

For comparative meta-analyses, review manager (RevMan - version 5.4.1) was used to analyze data acquired from included studies. We demonstrated pooled continuous effect measures as the mean difference (MD) with CI of $95 \%$. I2 tests were used to express between-study statistical heterogeneity, which describes true variation across studies as a percentage, where values around $25 \%$ indicates low heterogeneity, 50\% medium, and 75\% high heterogeneity among studies. Random-effects model was implemented in all analyses ${ }^{(\mathbf{1 3})}$. Inter-rater agreement was calculated using Krippendorff's Alpha-Reliability (0.955). We couldn't assess Publication bias because of the scarcity of included studies.

\section{RESULTS \\ Trial flow:}

A total of 628 references resulted from database searching. When duplicates were removed, a total of 582 references were screened by title. Of these, 29 articles were screened by abstract, 27 met the inclusion criteria. After a full-text review, only 11 studies managed to meet the requirements of the review (Figure 1).

Any disagreement during references screening process was settled by discussion. An update of the search has been conducted using the same keywords to the same databases until 7th July 2021. 171 references were found. Then duplicates were removed, 151 references were checked by title of these 6 articles screened by abstract, none met our eligibility criteria. 


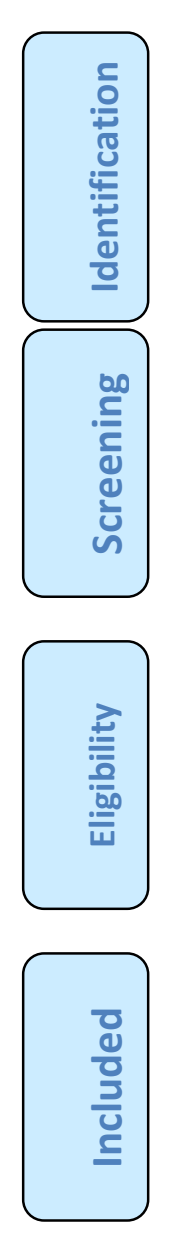

Study characteristics:

Characteristics of the studies are shown in (Table 2)

Participants:

In total 358 adults with subacromial shoulder pain, with ages over 18 years. The number of participants ranged from 20 to $60^{(14,15)}$. All examined trials included both males and females.

\section{Interventions:}

All included RCTs used Mulligan's MWM as an experimental group versus other treatment or no treatment. Nine of included trials used posterolateral mobilization (14, 16, 17, 18, 19, 20, 21, 22, and 23). Two of included trials used inferior mobilization (Hand behind back) ${ }^{(\mathbf{1 5}, \mathbf{2 4})}$. Five trials compared MWM to exercise using rotator cuff strengthening and scapular stabilization ${ }^{\left({ }^{(18)} \text {. Djordjevic } \boldsymbol{e t}\right.}$ al. ${ }^{(14)}$, Neelapala et al. ${ }^{(20)}$ and Satpute et al. ${ }^{(24)}$ used active ROM exercises. Moreover, Srivastava et al. ${ }^{(21)}$, Satpute et al. ${ }^{\text {(24) }}$ used isometric strengthening exercises. Three trials used sham as a comparator ${ }^{(16,17,22)}$. Two trials examined the effect of shoulder joint mobilization against
Additional records identified through other sources

Records excluded

original $(\mathrm{n}=553)$ update $(\mathrm{n}=145)$

Full-text articles excluded, with reasons original $(n=16)$ update $(n=6)$

-Not found as a full paper.

-Not related to our scope.
Studies included in

quantitative synthesis

(meta-analysis)

$(\mathrm{n}=3)$

\section{Figure (1): PRISMA flow chart.}

MWM (18, 15). One trial compared traditional treatment (exercise, ultrasound, and TENS) with MWM ${ }^{(\mathbf{1 9})}$. One trial compared the use of MWM alone to MWM in addition to Kinesio tape ${ }^{(23)}$. Physician advice only was given in one trial ${ }^{(\mathbf{1 8})}$.

\section{Outcome measures:}

All of the included studies measured change in ROM except Neelapala et al. ${ }^{(20)}$. Five trials used visual analogue scale (VAS) for measurement of change in pain intensity (21, 19, 20, 24, and 18). One trial measured change in PVAS ${ }^{(23)}$. Another one measured change in numerical pain rating system (NPRS) ${ }^{(16)}$. Two trails used pressure pain threshold (PPT) to measure changes in pain intensity (22, 23). Four trials estimated upper limb functionality using shoulder pain and disability index (SPADI) ${ }^{(\mathbf{1 7}, \mathbf{2 4}, \mathbf{2 1})}$. Two trials used Disabilities of Arm, Shoulder, and Hand $(\mathrm{DASH}){ }^{(\mathbf{1 9}, \mathbf{1 7})}$. One trial used SF-36 questionnaire ${ }^{(\mathbf{1 9})}$. For evaluating shoulder instability one trial used Oxford Shoulder Instability (OSI) score ${ }^{(\mathbf{1 5})}$. One trial measured the changes in shoulder rotators and scapular upward rotation strength ${ }^{(20)}$. 
Table (2): Characteristics of included studies

\begin{tabular}{|c|c|c|c|c|c|c|c|c|}
\hline \multirow{2}{*}{$\begin{array}{l}\text { Author/ } \\
\text { year }\end{array}$} & \multicolumn{4}{|l|}{ Population } & \multicolumn{2}{|l|}{ Intervention } & \multirow{2}{*}{$\begin{array}{l}\text { Outcome } \\
\text { measures }\end{array}$} & \multirow[t]{2}{*}{ Results } \\
\hline & $\mathrm{N}$ & Age & Gender & BMI & Intervention & Control & & \\
\hline 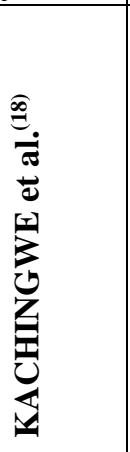 & $\begin{array}{l}\text { MWM: } 9 \\
\text { Mobilization: } 9 \\
\text { Control: } 7 \\
\text { Exercise: } 8\end{array}$ & $\begin{array}{l}\text { MWM: } \\
48.9 \pm \\
13.7 . \\
\text { Mobilizati } \\
\text { on: } 43.4 \pm \\
14.7 \\
\text { Control: } \\
45.6 \pm 13.0 \\
\text { Exercise: } \\
47.3 \\
\pm 20.1\end{array}$ & & & $\begin{array}{l}\text { Posterolateral MWM } \\
10 \text { reps/3 sets. }\end{array}$ & $\begin{array}{l}\text { Control: physician advice. } \\
\text { Mobilization: grade I-IV } \\
\text { joint mobilizations } \\
\text { Exercise: rotator cuff } \\
\text { strengthening and scapular } \\
\text { stabilization }\end{array}$ & $\begin{array}{l}\text { ROM } \\
\text { VAS } \\
\text { SPADI }\end{array}$ & $\begin{array}{l}\text { VAS scores revealed statistically significant } \\
\text { improvement in pain intensity from pre- to post- } \\
\text { treatment on the }[\mathrm{F}(1,29)=28.5, \mathrm{P}<.001 \eta \mathrm{p} 2=.50 \text {, } \\
\text { observed power }=.99] . \text { On the other hand, no } \\
\text { statistically significant differences were found on } \\
\text { the interaction between the four groups and mean } \\
\text { change from pre to post-treatment }\end{array}$ \\
\hline 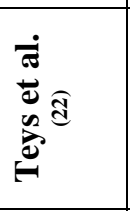 & 24 & $\begin{array}{l}46.1+9.86 \\
(20-64)\end{array}$ & & & $\begin{array}{l}\text { postero-lateral glide } \\
(\mathrm{MWM}) .10 \text { Reps./3 } \\
\text { sets. }\end{array}$ & Sham & $\begin{array}{l}\text { ROM } \\
\text { PTT }\end{array}$ & $\begin{array}{l}\text { ROM: mean improvement of } 16 \text {, compared with } 4 \\
\text { for the sham and no change for the control. } \\
\text { PTT: mean differences between the MWM and } \\
\text { Sham } 45 \mathrm{kPa} \text { and between MWM and Control } 46 \\
\mathrm{kPa}\end{array}$ \\
\hline 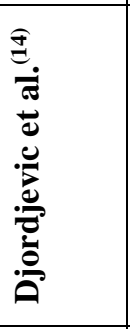 & $\begin{array}{l}\text { Group 1: } \\
10 \\
\text { Group 2: } \\
10\end{array}$ & $\begin{array}{l}\text { Group 1: } \\
51.80 \pm 5.3 \\
\text { Group 2: } \\
54.10 \pm 6.8\end{array}$ & $\begin{array}{l}\text { Group } \\
1: \\
4 \mathrm{~m} / 6 \mathrm{f} \\
\text { Group } \\
2: \\
3 \mathrm{~m} / 7 \mathrm{f}\end{array}$ & & $\begin{array}{l}\text { Posterolateral } \\
\text { glide(MWM). } 10 \\
\text { sessions with } 24 \\
\text { hours between } \\
\text { sessions. } \\
\text { a standard 5-cm } \\
\text { black Kinesio Tex } \\
\text { tape Taping. }\end{array}$ & $\begin{array}{l}\text { Initial exercise program for } \\
\text { impingement syndrome: } \\
\text { pendulum exercises and } \\
\text { pain-limited, active ROM } \\
\text { and strengthening exercises }\end{array}$ & ROM & $\begin{array}{l}\text { MWM and kinesotape compared to exercise } \\
\text { alone, which resulted in some improvement in } \\
\text { ROM but was not statistically significant. By day } \\
10 \text { the mean flexion range was } 166 \pm 20.59 \text { for the } \\
\text { MWM group compared to } 86 \pm 21.89 \text { for the } \\
\text { exercise group, abduction means range was } \\
170 \pm 17.89 \text { for the MWM group compared to } \\
60.5 \pm 15.72 \text { for exercise only group. }\end{array}$ \\
\hline 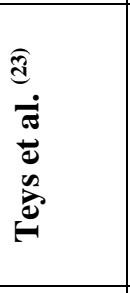 & 25 & $\begin{array}{l}45.4 \pm \\
14.8\end{array}$ & $\begin{array}{l}\mathrm{M} / \mathrm{F}: \\
15 / 10\end{array}$ & & $\begin{array}{l}\text { A single session of } \\
\text { posterolateral MWM } \\
10 \text { reps./3 sets } \\
\text { followed by a one- } \\
\text { week washout. one } \\
\text { session of MWM } \\
\text { with tape. }\end{array}$ & $\begin{array}{l}\text { A single session of } \\
\text { posterolateral MWM } 10 \\
\text { reps.//3 sets with tape } \\
\text { followed by a one-week } \\
\text { washout. a single session of } \\
\text { MWM only }\end{array}$ & $\begin{array}{l}\text { ROM } \\
\text { PPT } \\
\text { PVAS }\end{array}$ & $\begin{array}{l}\text { MWM-with Tape was superior to the MWM as } \\
\text { revealed by post hoc test. ROM improved } \\
\text { immediately post-intervention, at } 24 \text {-h and one- } \\
\text { week follow-up. the difference in MWM was } \\
\text { immediately post-intervention and at } 30 \text {-min } \\
\text { follow-up, but not beyond. }\end{array}$ \\
\hline 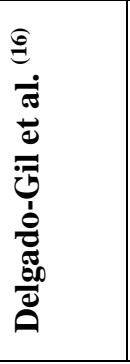 & $\begin{array}{l}\text { MWM: } 21 \\
\text { Sham: } 21\end{array}$ & $\begin{array}{l}\text { MWM: } \\
55.4 \pm 7.8 \\
\text { Sham: : } \\
54.3 \pm 10\end{array}$ & & & $\begin{array}{l}\text { posterolateral MWM } \\
10 \text { reps./3 sets. } \\
\text { The approximate } \\
\text { length of each } \\
\text { treatment session was } \\
10 \text { minutes }\end{array}$ & $\begin{array}{l}\text { The sham condition } \\
\text { replicated the treatment } \\
\text { condition } \\
\text { except for the hand } \\
\text { positioning. The } \\
\text { approximate length of each } \\
\text { treatment session was } \\
10 \text { minutes. }\end{array}$ & $\begin{array}{l}\text { ROM } \\
\text { NPRS }\end{array}$ & $\begin{array}{l}\text { Found that pain free shoulder joint flexion ROM, } \\
\text { maximum external rotation and maximum } \\
\text { shoulder flexion improved significantly after } 4 \\
\text { sessions of mobilization. results were better than } \\
\text { patients who were in the sham group. Large } \\
\text { between-group effect (SMD, 0.9) in favor of the } \\
\text { MWM group regarding shoulder pain. Within- } \\
\text { group effect sizes were low (SMD }<0.26) \\
\text { regarding the abduction. }\end{array}$ \\
\hline
\end{tabular}


https://ejhm.journals.ekb.eg/

\begin{tabular}{|c|c|c|c|c|c|c|}
\hline 产 & $\begin{array}{l}\text { MWM: } 22 \\
\text { Exercise: } 22\end{array}$ & $\begin{array}{l}\text { MWM: } \\
53.41 \pm 7.0 \\
8 . \\
\text { Exercise: } \\
52.41 \pm 7.0 \\
6\end{array}$ & $\begin{array}{l}\text { MWM ( hand behind } \\
\text { back), } 10 \text { reps/ } 3 \text { sets. } \\
\text { Hot pack. } \\
\text { Exercise. }\end{array}$ & $\begin{array}{l}\text { Hot pack. } \\
\text { Exercise. }\end{array}$ & $\begin{array}{l}\text { ROM } \\
\text { VAS } \\
\text { SPADI }\end{array}$ & $\begin{array}{l}\text { Significant difference was found in shoulder } \\
\text { internal rotation ROM of } 16.86^{\circ} \text { in the MWM- } \\
\text { with-exercise group compared to } 7.38^{\circ} \text { in the } \\
\text { exercise group. }\end{array}$ \\
\hline 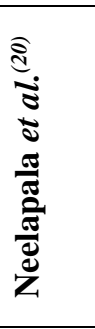 & $\begin{array}{l}\text { MWM: } 15 \\
\text { Control: } 16\end{array}$ & $\begin{array}{l}\text { MWM: } \\
40.23 \pm 10 . \\
55 \\
\text { Control: } \\
42.41 \pm 10 \text {. } \\
38\end{array}$ & $\begin{array}{l}\text { Posterolateral MWM } \\
5 \text { reps. } 3 \text { sets. } \\
3 \text { sessions. }\end{array}$ & $\begin{array}{l}\text { Active ROM of the } \\
\text { shoulder within the pain- } \\
\text { free range One set of } 10 \\
\text { reps. of active shoulder } \\
\text { movements. }\end{array}$ & $\begin{array}{l}\text { VAS } \\
\text { shoulder } \\
\text { rotator } \\
\text { strength, } \\
\text { and } \\
\text { scapular } \\
\text { upward } \\
\text { rotation. }\end{array}$ & $\begin{array}{l}\text { Compared to active exercise alone, posterolateral } \\
\text { mobilization with movement reduced pain } \\
\text { effectively and improved the strength of external } \\
\text { rotators inpatients complaining of painful } \\
\text { shoulders after 3-5 days. Significant external } \\
\text { rotation strength and pain differences were } \\
\text { detected between the groups after intervention. }\end{array}$ \\
\hline 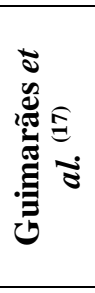 & $\begin{array}{l}\text { MWM: } 14 \\
\text { Sham: } 13\end{array}$ & $\begin{array}{l}\text { MWM: } \\
30.3 \pm 6.9 \\
\text { Sham: } \\
31.9 \pm 9.2\end{array}$ & $\begin{array}{l}\text { Posterolateral MWM } \\
10 \text { reps/ } 3 \text { sets ( } 4 \\
\text { sessions). } \\
\text { Rest and } \\
\text { reassessment. } \\
\text { Sham condition ( } 4 \\
\text { sessions). }\end{array}$ & $\begin{array}{l}\text { Sham condition ( } 4 \\
\text { sessions). } \\
\text { Rest and reassessment. } \\
\text { Posterolateral MWM } 10 \\
\text { reps/ } 3 \text { sets ( } 4 \text { sessions). }\end{array}$ & $\begin{array}{l}\text { ROM } \\
\text { DASH } \\
\text { SPADI }\end{array}$ & $\begin{array}{l}\text { Sham had a similar effect to MWM in improving } \\
\text { shoulder external rotation range and abduction, } \\
\text { pain, and function in patients with shoulder } \\
\text { impingement syndrome. Only abduction } \\
\text { movement and SPADI Pain overcame the clinical } \\
\text { relevance threshold. The isometric peak force } \\
\text { tests detected no improvement. }\end{array}$ \\
\hline 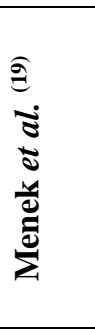 & $\begin{array}{l}\text { MWM: } 15 \\
\text { Control: } 15\end{array}$ & $\begin{array}{l}\text { MWM: } \\
51.73 \pm \\
6.64 \\
\text { Control: } \\
50.26 \pm \\
4.28\end{array}$ & $\begin{array}{l}\text { Posterolateral MWM } \\
10 \text { reps/ } 3 \text { sets. } \\
\text { Traditional } \\
\text { physiotherapy } \\
\text { applications }\end{array}$ & $\begin{array}{l}\text { Traditional physiotherapy } \\
\text { applications(stretching } \\
\text { exercises, cold pack, } \\
\text { ultrasound, Transcutaneous } \\
\text { Electrical Nerve } \\
\text { Stimulation (TENS), finger } \\
\text { staircase, Codman and } \\
\text { wand exercises) }\end{array}$ & $\begin{array}{l}\text { ROM } \\
\text { VAS } \\
\text { DASH } \\
\text { SF-36 }\end{array}$ & $\begin{array}{l}\text { VAS scores during activity and rest, shoulder } \\
\text { ROM, and DASH scores in the MWM group } \\
\text { were better than the control group ( } p<0.05) \text {., No } \\
\text { statistically significant difference was found in } \\
\text { SF- } 36 \text {. }\end{array}$ \\
\hline 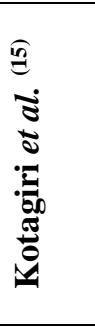 & $\begin{array}{l}\text { MWM: } 30 \\
\text { Mobilization: } \\
30\end{array}$ & $\begin{array}{l}\text { MWM: } \\
\text { Mobilizati } \\
\text { on: }\end{array}$ & $\begin{array}{l}\text { Inferior MWM } 4 \\
\text { times per week ( } 1 \text { st } \\
\text { day } 3 \text { glides, } 2 \text { nd day } \\
3 \text { sets of six glides, } \\
\text { 3rd day } 3 \text { sets of } 10 \\
\text { glides were given } \\
\text { and } 4 \text { th day again } 3 \\
\text { sets of } 10)\end{array}$ & $\begin{array}{l}\text { Mobilizations directed } \\
\text { toward the posterior capsule } \\
\text { with stabilization exercise. } \\
12 \text { minutes a minimum of } 4 \\
\text { times per week }\end{array}$ & $\begin{array}{l}\text { ROM } \\
\text { OSI }\end{array}$ & $\begin{array}{l}\text { Mulligan group showed significant improvement } \\
\text { in OSI score). } \\
\text { ROM showed significant increase in the range of } \\
\text { internal rotation by } 33.00 \pm 7.83 \text { degrees compared } \\
\text { to } 20.83 \pm 8.10 \text { degrees. }\end{array}$ \\
\hline 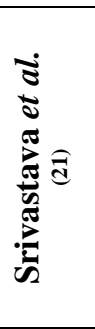 & 22 & $\begin{array}{l}\text { MWM: } \\
50.09 \\
\pm 11.36 \\
\text { Cryothera } \\
\text { py: } 41.91 \\
\pm 11.22\end{array}$ & $\begin{array}{l}\text { Posterolateral MWM } \\
10 \text { reps/ } 3 \text { sets. } \\
\text { One session every } \\
\text { day. }\end{array}$ & $\begin{array}{l}\text { Cryotherapy } 20 \text { minutes . } \\
\text { Isometric strengthening } \\
\text { exercise }\end{array}$ & $\begin{array}{l}\text { ROM } \\
\text { VAS } \\
\text { SPADI }\end{array}$ & $\begin{array}{l}\text { MWM group VAS (MD) 1st day }=0.9 \\
\text { (MD) 6th day }=2.36 \\
\text { ROM (MD) } 1 \text { st day }=6.79 \\
\text { (MD) 6th day }=23.63 \\
\text { cryotherapy group VAS(MD) } 1 \text { st day }=0.456 \\
\text { (MD) 6th day }=3.096 \\
\text { ROM (MD) } 1 \text { st day }=3.13 \\
\text { (MD) 6th day }=21.82\end{array}$ \\
\hline
\end{tabular}




\section{Risk of bias (ROB) in included studies:}

For assessing the risk of bias we used Cochrane risk-of-bias tool for randomized trials (RoB 2) Version 22 August 2019 assessment tool ${ }^{(25)}$. The reviewers had some concerns regarding the risk of bias for 5 of the included studies ${ }^{(16,17,18,}$ ${ }^{22,23)}$. 4 studies were rated to be of low risk ${ }^{(14,20,21,24)}$. Two studies had been rated as high risk ${ }^{(\mathbf{1 5}, \mathbf{1 9})}$. All the studies have no missing data and no non-protocol interventions had been applied (figure 2). Inter-rater agreement was calculated using Krippendorff's Alpha-Reliability (0.955).

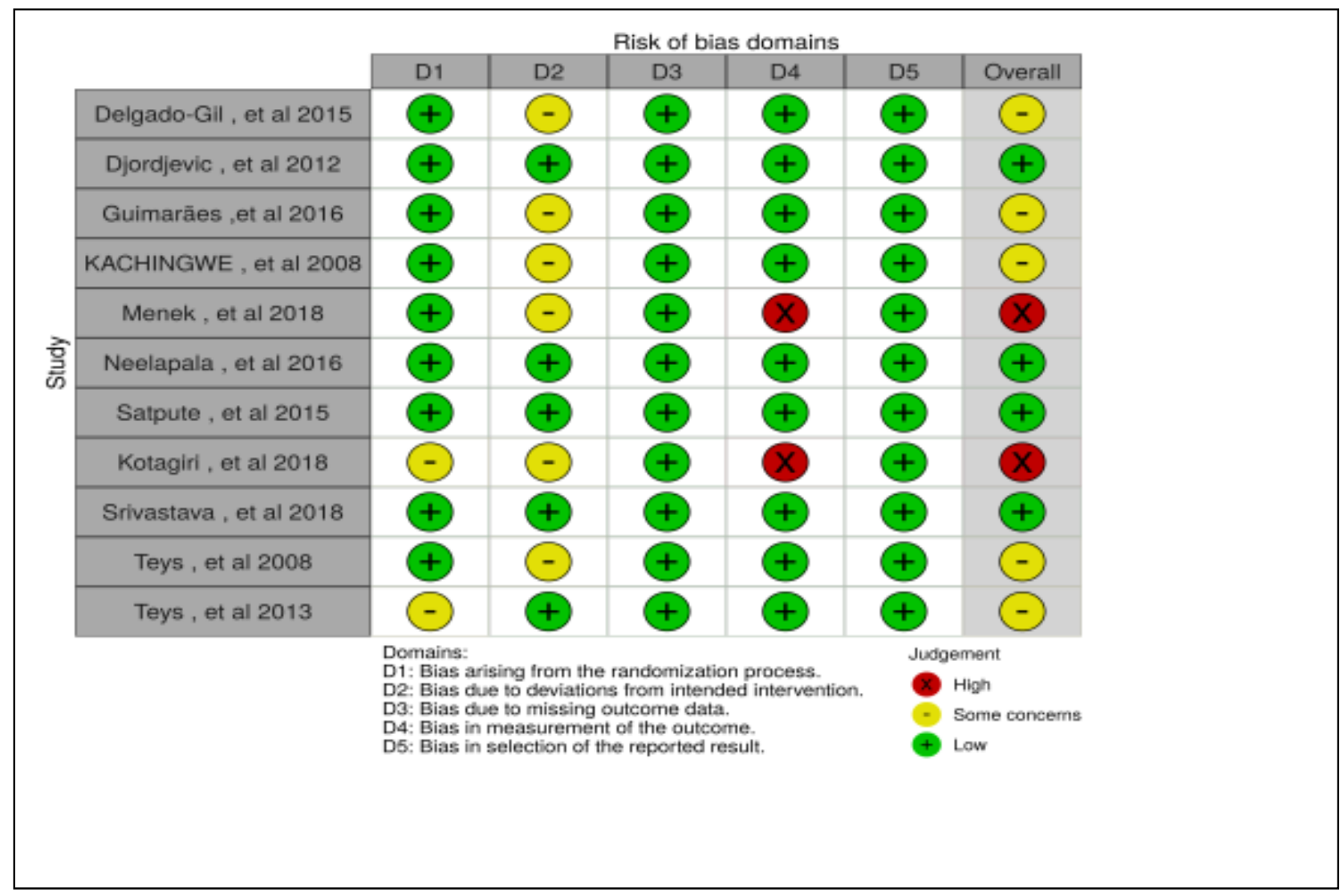

Figure (2): Risk of bias for domains.

\section{Mobilization with movement versus exercise:}

Kachingwe et $\boldsymbol{a l}$. (18) concluded that if we combined MWM with a supervised exercise program it will result in a better percentage of change (statistically insignificant). VAS percentage of change was $55.2 \pm 31.9$ after completing the treatment compared to $20.8 \pm 112.3$ for supervised exercise only. Not only improvement in pain was noted, but also the function was improved in relation to control group or exercise group. VAS test $[\mathrm{F}$ $(1,29)=28.5, \mathrm{P}<.001, \eta \mathrm{p}^{2}=.50$, observed power $\left.=.99\right]$. Djordjevic et al. ${ }^{(14)}$ applied posterolateral MWM and kinesotape compared to exercise alone, which resulted in some improvement in ROM but was not statistically significant. This may be a useful modality in improving the active range of movement in the painful shoulder. By day 10 the mean flexion range was $166 \pm 20.59$ for the MWM group compared to $86 \pm 21.89$ for the exercise group, mean abduction range was $170 \pm 17.89$ for the MWM group compared to $60.5 \pm 15.72$ for exercise only group. Satpute et al. ${ }^{(24)}$ detected a statistical significant difference in pain and internal rotation ROM when HBB
MWM with exercise applied to individuals complaining of acute shoulder pain and disability compared to hot packs and exercise group. In addition, the difference was of a clinical meaning because it passed the minimum clinically important difference of $1.4 \mathrm{~cm}$ on the VAS, 38 the MDC of $6.1^{\circ}$ for shoulder internal rotation ROM, and the MDC of 18 points for the SPADI score. Neelapala $e t$ al. (20) found that compared to active exercise alone, posterolateral mobilization with movement reduced pain effectively and improved the strength of external rotators in patients complaining of painful shoulders after 3-5 days. Significant external rotation strength and pain differences were detected between the groups after intervention. After treatment, VAS scores $(\mathrm{F}(1,29)=27$, $\mathrm{p}<0.01)$ and Shoulder external rotator strength $(\mathrm{F}(1,29)$ $=4.6, \mathrm{p}=0.04)$. However, no significant internal rotator strength was detected $(\mathrm{F}(1,29)=0.03, \mathrm{p}=0.8)$ and scapular upward rotation $(\mathrm{F}(1,29)=0.09, \mathrm{p}=0.7)$ posttreatment. Srivastava et al. ${ }^{(21)}$ at the end of six treatment sessions both therapies showed similar results. However, for immediate improvement in ROM and pain, 
mobilization can be given to patients with shoulder impingement. MWM group VAS mean diff. (1st day = $0.9,6$ th day $=2.36)$, ROM mean diff. $(1$ st day $=6.79,6$ th day $=23.63$ ). Exercise/Ice group VAS mean diff. (1st day $=0.456$, 6th day $=3.096)$, ROM mean diff. $(1 \mathrm{st}$ day $=$ 3.13 , 6th day $=21.82$ ).

\section{Mobilization with movement versus Sham or no treatment:}

Kachingwe et al. ${ }^{(18)}$ had patients that only took physician advice and compared them to patients who received MWM combined with supervised exercise program and found a higher percentage of change (without statistical significance) comparing pre- to posttreatment values in decreasing pain and improving function compared to control group. Percentage of change with MWM in VAS was $55.2 \pm 31.9$ compared to $14.4 \pm$ 119.8. Teys et al. ${ }^{(22)}$ found that after 3 sessions of MWM can be of benefit to patients with painful limited elevation of shoulder. It lead to an early improvement in ROM and PPT. Mean ROM improvement of $16^{\circ}$, compared with $4^{\circ}$. No change was detected for the control group. Mean PPT differences between the MWM and sham was $45 \mathrm{kPa}$ and between MWM and control was 46kPa. Delgado-Gil et al. ${ }^{(16)}$ found that pain free shoulder joint flexion ROM, maximum external rotation and maximum shoulder flexion improved significantly after 4 sessions of mobilization. Results were better than sham group patients were. Large between-group effect (SMD, 0.9) in favor of the MWM group regarding shoulder pain. Within-group effect sizes were low (SMD <0.26) regarding the abduction. Guimarães et al. ${ }^{(17)}$ concluded that sham had a similar effect to MWM in increasing shoulder external rotation range and abduction, improving pain, and function in patients with shoulder impingement syndrome.

\section{Meta-analysis:}

To analyze the impact of MWM on subacromial impingement compared to exercise regarding improvement of pain level, four studies qualified for meta-analysis. Unfortunately only the data of VAS scores from three could be obtained $(n=3)$ as one of the authors has been contacted to provide some results but no response detected. A total number of participants was 97 of those 48 who have received MWM, whereas for the impact of MWM compared to sham, SPADI data from two studies were collected $(n=2)$. A total number of participants were 66 of those 3 ) received MWM.

For VAS a significant statistical difference was detected favoring MWM in the forest plot shown in (Fig. 3) $-1.14(95 \%$ CI -2.12 to -0.15$)$ but was below the minimally clinical important difference (MCID) for VAS in patients with rotator cuff diseases, which was $1.4 \mathrm{~cm}$ (26). For SPADI a slight difference was detected towards MWM but not significantly shown in (Fig. 4) -6.56 (95\% CI -38.56 to 25.43 ).

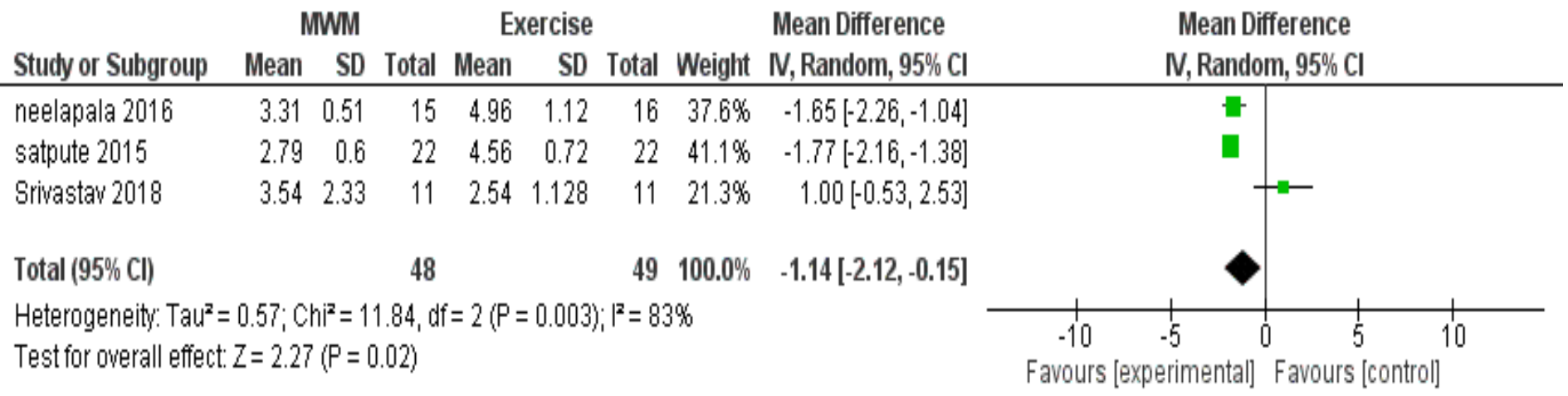

Figure (3): VAS forest plot.

\section{MWM Exercise Mean Difference Mean Difference}

$\begin{array}{llllll}\text { Study or Subgroup Mean SD Total Mean SD Total Weight } \quad \mathrm{N}, \text { Random, } 95 \% \mathrm{Cl} & \mathrm{N}, \text { Random, } 95 \% \mathrm{Cl}\end{array}$

\begin{tabular}{|c|c|c|c|c|c|c|}
\hline satpute 2015 & $23.86 \quad 6.05$ & $\begin{array}{lll}22 & 46.04 \quad 5.33\end{array}$ & $2252.2 \%$ & $-22.18[-25.55,-18.81]$ & $\bar{\square}$ & \\
\hline Srivastav 2018 & $30.82 \quad 21.85$ & $\begin{array}{lll}11 & 20.32 & 8.72\end{array}$ & $1147.8 \%$ & $10.50[-3.40,24.40]$ & & \\
\hline Total (95\% Cl) & & 33 & $33 \quad 100.0 \%$ & $-6.56[-38.56,25.43]$ & & \\
\hline \multicolumn{5}{|c|}{$\begin{array}{l}\text { Heterogeneity: Tau }{ }^{2}=507.36 ; \mathrm{Chi}^{2}=20.05, \mathrm{df}=1(\mathrm{P}<0.00001) ; \mathrm{I}^{2}=95 \% \\
\text { Test for overall effect: } Z=0.40(P=0.69)\end{array}$} & $\begin{array}{cc}-100 & -50 \\
\text { Favours [experimenta }\end{array}$ & $\begin{array}{ccc}0 & 50 & 100 \\
\text { Favours [control] }\end{array}$ \\
\hline
\end{tabular}

Figure (4): SPADI forest plot. 
The current review examined the evidence related to the effects of MWM alone, combined with exercise, joint mobilization, or kinesotape as a treatment for subacromial pain compared to heat therapy, exercise only, mobilization, sham manual contact, and traditional physiotherapy.

Eleven RCTs were contained in the current review. Risk of bias ranged from low to high, which affected the results of our study. Therefore, based on some studies in our review conclusive evidence cannot be reached. The inconsistent findings among studies may be due to lack of a number of the studies in the literature or due to small sample sizes.

Based on the available evidence from ten studies in the current review $(\mathbf{1 4 , 1 5 , 1 6 , 1 8 , 1 9 , 2 0 , 2 1 , 2 2 , 2 3 , 2 4 )}$, these results varied among outcomes as MWM was effective at decreasing pain and enhancing outcomes immediately and in short-term ranging from 3 days up to 6 weeks. These findings of improving pain and function agree with the results of previous reviews ${ }^{(11,27)}$. On the other hand, one study found that MWM was no better than sham in reducing pain or improving function ${ }^{(17)}$.

Based on 2 RCTs pooled meta-analysis $(n=66)$ on the effect of MWM on shoulder functional outcome, insignificant difference $(\mathrm{P}>0.05)$ in changes of SPADI scores was found between MWM and exercise. The presence of high heterogeneity between included studies was $\left(I^{2}=95 \%\right)$ due to the scarcity of included studies subgroup analysis that could not be obtained.

Based on 3 RCTs pooled meta-analysis $(n=97)$ on the effect of MWM on pain score, significant difference was detected $(\mathrm{P}<0.05)$ in changes of VAS scores in favor of MWM. The presence of high heterogeneity between included studies was noted among studies $\left(I^{2}=83 \%\right)$ because subgroup analysis could not be obtained because of low number of included studies. In addition, the presence or absence of publication bias on these outcomes could not be determined.

From this review, it can be inferred that integrating MWM with shoulder impingement-based exercises produces better outcomes regarding pain and ROM as reported by Srivastava $\boldsymbol{e t}$ al. ${ }^{(21)}$ an immediate improvement has been noted in pain and ROM in the posterolateral MWM group compared to exercise and cold application group. However, there was a similar improvement after completing the treatment in the two groups of pain, ROM, and function. Also, Neelapala $\boldsymbol{e t}$ al. ${ }^{(20)}$ reported not only an improvement of pain level but also in external rotation strength compared to the exercise-only group. However, no significant difference between both groups could be detected in terms of internal rotation strength or scapular upward rotation posttreatment.

Satpute et al. ${ }^{(24)}$ added the Hand behind back (HBB) MWM to exercise and found a significant internal rotation ROM improvement, as well as diminished pain and disability. MWM combined with exercise used by Kachingwe et al. (18) also produced better results compared to both the exercise-only group and control group in pain levels and AROM. Combined with kinesiotape, MWM had a quicker effect than an exercise in improving ROM. On the other hand, by the end of treatment, they both had a similar effect increasing ROM according to Guimarães $\boldsymbol{e t}$ al. ${ }^{\left({ }^{(17)}\right.}$. Applying a rigid sports tape immediately after MWM produced a longer-lasting effect than MWM alone up to one week post-intervention regarding improved ROM as described by Teys et al. ${ }^{(23)}$.

Delgado-Gil et al. ${ }^{(16)}$ compared MWM to sham manual contact, which replicated the same hand positioning as the MWM and found that the MWM had a much more significant pain intensity improvement than the sham group during shoulder flexion, pain-free flexion ROM and maximum ROM of both flexion and external rotation. On the other hand, Guimarães et al. ${ }^{(17)}$ had a completely different conclusion, which is that MWM was no better than sham in reducing pain, improving function, or increasing ROM of shoulder abduction and external rotation. Teys et al. ${ }^{(22)}$ added that MWM had a much significant difference in ROM and pain pressure threshold than sham manual contact. Kotagiri et al. ${ }^{(15)}$ tested HBB MWM with stretching against exercise with mobilization on limited internal rotation of the glenohumeral joint and detected a significant difference in internal rotation ROM favoring the MWM group. Menek et al. ${ }^{(19)}$ examined the value of adding MWM to the traditional physiotherapy applications against traditional physiotherapy applications only (Ice, TENS, US, and exercise) and found a benefit to the addition of MWM to the traditional applications in terms of pain level, ROM, DASH and SF36.

\section{Strengths and Limitations:}

One of the strengths of this review was the use of a meticulous searching strategy and only randomized control trials have been included. To assess the level of bias among the studies of the Cochrane risk of bias, tool (ROB2) was used. To our knowledge, there is no systematic review to date that used MWM for subacromial impingement.

As for limitations, the small number of studies in the literature that investigated MWM for subacromial impingement, small sample sizes for some of the included studies, the potential bias in some of the included studies that arose from lack of blinding, and limitations of pooling data into meta-analysis due to the variability of received interventions between included studies with different outcome measures.

\section{Clinical implications:}


Mulligan's mobilization with movement may be beneficial as a part of a multi-modal approach in treating subacromial shoulder pain. As per this review, MWM is more effective with exercise than exercise alone producing short-term improvements in pain, ROM, and functional limitation. Applying a rigid sports tape immediately after MWM can extend the duration of improved symptoms. The short-term effect has to be in mind when constructing a rehabilitative program for those patients. To deduce conclusive evidence more research has to be done on the effectiveness of MWM.

\section{CONCLUSION}

Shoulder mobilization with movement combined with a monitored exercise program has a better impact on pain levels, ROM, and functional limitations than exercise alone or sham in short-term with similar longterm improvement to exercise.

\section{RECOMMENDATIONS}

More future research with sufficient sample size and appropriate blinding.

\section{Financial support and sponsorship: Nil.}

\section{Conflict of Interest: Nil.}

\section{REFERENCES}

1. Ludewig $\mathbf{P}$, Cook $\mathbf{T}$ (2000): Alterations in shoulder kinematics and associated muscle activity in people with symptoms of shoulder impingement. Physical Therapy, 80.3: 276-291.

2. Conroy D, Hayes K (1998): The effect of joint mobilization as a component of comprehensive treatment for primary shoulder impingement syndrome. Journal of Orthopaedic \& Sports Physical Therapy, 28: 3-14.

3. Decker M, Hintermeister R, Faber $\mathrm{K}$ et al. (1999): Serratus anterior muscle activity during selected rehabilitation exercises. The American Journal of Sports Medicine, 27: 784-791.

4. Machner A, Merk H, Becker R et al. (2003): Kinesthetic sense of the shoulder in patients with impingement syndrome. Acta Orthopaedica Scandinavica, 74: 85-88.

5. Michener $L$, Walsworth $M$, Burnet $E$ (2004): Effectiveness of rehabilitation for patients with subacromial impingement syndrome: a systematic review. Journal of Hand Therapy, 17: 152-164.

6. Bang M, Deyle G (2000): Comparison of supervised exercise with and without manual physical therapy for patients with shoulder impingement syndrome. Journal of Orthopaedic \& Sports Physical Therapy, 30: 126-137.

7. Faber E, Kuiper J, Burdorf A et al. (2006): Treatment of impingement syndrome: a systematic review of the effects on functional limitations and return to work. Journal of Occupational Rehabilitation, 16: 6-24.

8. Krukowska J, Zbrzezna B, Czernicki J (2009): Effects of cold on physiotherapy in patients with painful shoulder syndrome. Physiotherapy, 17: 19-27.
9. Haik M, Alburquerque-Sendín $\mathrm{F}$, Moreira $\mathrm{R}$ et al. (2016): Effectiveness of physical therapy treatment of clearly defined subacromial pain: a systematic review of randomized controlled trials. Br J Sports Med., 50: 11241134.

10. Mulligan B (2003): The painful dysfunctional shoulder. A new treatment approach using "Mobilisation with Movement". New Zealand Journal of Physiotherapy, 31 (3): $140-142$.

11. Stathopoulos N, Zacharias D, George A (2019): Effectiveness of Mulligan's mobilization with movement techniques on a range of motion in peripheral joint pathologies: a systematic review with meta-analysis between 2008 and 2018. Journal of Manipulative and Physiological Therapeutics, 42: 439-449.

12. Moher D, Liberati A, Tetzlaff $J$ et al. (2009): The PRISMA Group. Preferred Reporting Items for Systematic Reviews and Meta-Analyses: The PRISMA Statement. PLoS Med., 6(7): e1000097.

13. DerSimonian R, Laird $\mathbf{N}$ (1986): Meta-analysis in clinical trials. Controlled Clinical Trials, 7 (3): 177-188.

14. Djordjevic O, Vukicevic D, Katunac $L$ et al. (2012): Mobilization with movement and kinesiotaping compared with a supervised exercise program for painful shoulder: results of a clinical trial. Journal of Manipulative and Physiological Therapeutics, 35: 454-463.

15. Kotagiri S, Songa A, Gad M et al. (2018): Effectiveness of Mobilization with Exercise V/S Mulligan Internal Rotation MWM with Stretching in Patient with Glenohumeral Internal Rotation Deficit. International Archives of Medicine, 5 (5): 138-145.

16. Delgado-Gil J, Prado-Robles E, Rodrigues-de-Souza D et al. (2015): Effects of mobilization with movement on pain and range of motion in patients with unilateral shoulder impingement syndrome: a randomized controlled trial. Journal of Manipulative and Physiological Therapeutics, 38: 245-252.

17. Guimarães J, Salvini T, Siqueira A et al. (2016): Immediate effects of mobilization with movement vs sham technique on a range of motion, strength, and function in patients with shoulder impingement syndrome: a randomized clinical trial. Journal of Manipulative and Physiological Therapeutics, 39: 605-615.

18. Kachingwe A, Phillips B, Sletten E et al. (2008): Comparison of manual therapy techniques with therapeutic exercise in the treatment of shoulder impingement: a randomized controlled pilot clinical trial. Journal of Manual \& Manipulative Therapy, 16: 238-247.

19. Menek B, Devrim $T$ and CandanAlgun $Z$ (2019): The effect of Mulligan mobilization on pain and life quality of patients with Rotator cuff syndrome: A randomized controlled trial. Journal of Back and Musculoskeletal Rehabilitation, 32: 171-178.

20. Neelapala R, Reddy R, Danait R (2016): Effect of mulligan's posterolateral glide on shoulder rotator strength, scapular upward rotation in shoulder pain subjects-a randomized controlled trial. Journal of Musculoskeletal Research, 19: 1650014.

21. Srivastava S, Charu E, Harramb M (2018): Comparison of Mobilisation with Movement and 
Cryotherapy in Shoulder Impingement Syndrome-A Randomised Clinical Trial. Journal of Clinical \& Diagnostic Research, 12 (10): 1-5.

22. Teys P, Leanne B, Bill V (2008): The initial effects of a Mulligan's mobilization with movement technique on a range of movement and pressure pain threshold in painlimited shoulders. Manual Therapy, 13: 37-42.

23. Teys P, Bisset L, Collins $\mathbf{N}$ et al. (2013): One-week time course of the effects of Mulligan's Mobilisation with Movement and taping in painful shoulders. Manual Therapy, 18: 372-377.

24. Satpute K, Prashant B, Toby H (2015): Efficacy of hand behind back mobilization with movement for acute shoulder pain and movement impairment: a randomized controlled trial. Journal of Manipulative and Physiological Therapeutics, 38: 324-334.
25. Sterne J, Savović J, Page M et al. (2019): RoB 2: a revised tool for assessing risk of bias in randomised trials. BMJ, 366: 14898.

26. Tashjian R, Deloach J, Porucznik C et al. (2009): Minimal clinically important differences (MCID) and patient acceptable symptomatic state (PASS) for visual analog scales (VAS) measuring pain in patients treated for rotator cuff disease. J Shoulder Elbow Surg., 18 (6): 92732

27. Alalawi A, Alshehri M, Alhasan H (2017): The Effectiveness of Mulligan's Mobilization with Movement in the Management of Shoulder Impingement Syndrome: A Systematic Review. https://www. researchgate.net/publication/321622245_

The_Effectiveness_of_Mulligan's_Mobilization_with_M ovement_in_the_Management_of_Shoulder_Impingeme nt_Syndrome_A_Systematic_Review 